Brit. J. prev. soc. Med. (1974), 28, 241-245

\title{
Price and consumption of cigarettes: a case for intervention?
}

\author{
JULIAN PETO* \\ MRC Tuberculosis and Chest Diseases Unit, London SW3 6HP
}

\section{SUMMARY}

It is suggested that cigarette consumption can and should be reduced by tax increases. As this contradicts a recent communication, the differences of analysis and the underlying models are discussed. Straightforward curve-fitting to serial social or economic data can be very misleading. If there is random drift, it is better to analyse consecutive changes of the parameters rather than their actual values.

\section{INTRODUCTION}

Atkinson and Skegg (1973) examined the demand for cigarettes with particular reference to the relationship with price and antismoking publicity. They found rather different results for men and women, concluding that men are responsive to publicity but not to price, while women respond to price but not at all to publicity. A strong dependence on income was found in both sexes. I shall deal only with demand in men, although the general principles I wish to discuss apply to both.

The equation fitted by Atkinson and Skegg is of the form:

1. $Q=\alpha Y+\beta P+\gamma_{1} d_{1}+\gamma_{2} d_{2}+\delta r+$ constant + error,

where capitals denote logarithms. The untransformed variables $q, y$, and $p$ are consumption (number of cigarettes per head), real per capita income, and real price, respectively. $d_{1}$ and $d_{2}$ are dummy variables to allow for the effects of the Royal College of Physicians report in 1962 and the ban on television advertising in 1965, and $r$ is the returning trend. $d_{1}$ is 0 until 1961 and 1 afterwards, $d_{2}$ is 0 until 1964 and 1 afterwards, and $r$ is 0 until 1962, then $1,2, \ldots .8$ in 1963 , $1964, \ldots \ldots$ 1970. Their corresponding estimates are shown in the first line of Table I. Thus it appears that price is irrelevant, income is the main predictor, and publicity reduced consumption transiently by $8 \%$ in both 1962 and 1965 . However, Russell (1973) compared annual changes in consumption and price between 1946 and 1971 and estimated $\beta$, the price elasticity, by fitting

2. $\Delta \mathrm{q} / \mathrm{q}=\boldsymbol{\beta} . \Delta \mathrm{p} / \mathrm{p}+$ error, which is approximately

3. $\Delta \mathrm{Q}=\boldsymbol{\beta} . \Delta \mathrm{P}+$ error.

( $\Delta$ denotes the change between consecutive years.) He found a price elasticity of -0.6 and observed that the signs of these changes were very significantly associated, 22 of 25 consumption changes coinciding with price changes of opposite sign

TABLE I

EQUATION (1): COMPARISON OF DEPENDENCE OF CIGARETTE CONSUMPTION ON INCOME AND LINEAR TREND (1951-70)

\begin{tabular}{|c|c|c|c|c|c|c|c|}
\hline Equation & $\underset{\mathbf{P}}{\text { Price }}$ & $\underset{\mathbf{Y}}{\text { Income }}$ & $\begin{array}{l}\text { Linear } \\
\text { Trend }\end{array}$ & $1962 \underset{d_{1}}{\text { Dummy }}$ & $1965 \underset{d_{2}}{\text { Dummy }}$ & $\begin{array}{c}\text { Return } \\
\text { Trend } \\
\mathbf{r}\end{array}$ & $\begin{array}{l}\text { Multiple } \\
\text { Correlation }\end{array}$ \\
\hline 1. Atkinson and Skegg .. & $\begin{array}{l}0.00 \\
(0.0)\end{array}$ & $\begin{array}{l}0 \cdot 34 \\
(7 \cdot 6)\end{array}$ & - & $\begin{array}{l}-0.078 \\
(4.9)\end{array}$ & $\frac{-0 \cdot 078}{(4 \cdot 1)}$ & $\begin{array}{l}0.0086 \\
(2 \cdot 6)\end{array}$ & 0.940 \\
\hline $\begin{array}{l}\text { 2. Replacing income by } \\
\text { linear trend } \ldots\end{array}$ & $\begin{array}{l}0 \cdot 05 \\
(0 \cdot 4)\end{array}$ & - & $\begin{array}{l}0 \cdot 012 \\
(7 \cdot 4)\end{array}$ & $\begin{array}{l}-0.081 \\
(4 \cdot 8)\end{array}$ & $\frac{-0.075}{(3.9)}$ & $\begin{array}{l}0.0029 \\
(0.8)\end{array}$ & 0.937 \\
\hline
\end{tabular}

Linear trend is 1, 2, ... 20 for 1951, 1952, .... 1970, $t$ values are given in parentheses beneath the coefficient estimates, $A$ value greater than about 2 indicates significance of less than 0.05 . *Present address: DHSS Cancer Epidemiology and Clinical Trials Unit, Department of the Regius Professor of Medicine, University of
Oxford. 
(P < 0.001). Atkinson and Skegg (1974), commenting on these results, do not discuss this highly significant association. They attribute the discrepancy between their conclusions and Russell's to four factors:

\begin{tabular}{|c|c|c|}
\hline Factor & Atkinson and Skegg & Russell \\
\hline 1. Period studied & $1951-70$ & $1946-71$ \\
\hline $\begin{array}{l}\text { 2. Consumption } \\
\text { variable }\end{array}$ & $\begin{array}{l}\text { Cigarettes/head, } \\
\text { adjusted for age } \\
\text { distribution }\end{array}$ & $\begin{array}{l}\text { Cigarettes/head } \\
\text { aged over } 15\end{array}$ \\
\hline 3. Model & Equation 1 & Equation 2 \\
\hline $\begin{array}{l}\text { 4. Price } \\
\text { variable }\end{array}$ & $\begin{array}{l}\text { Implicit price } \\
\text { deflation, intended to } \\
\text { allow for shifts to } \\
\text { small or filter } \\
\text { cigarettes }\end{array}$ & $\begin{array}{l}\text { Price of } 20 \text { standard } \\
\text { plain cigarettes/cost } \\
\text { of living }\end{array}$ \\
\hline
\end{tabular}

There are sound reasons for restricting the period of analysis and correcting consumption by age, and I have followed Atkinson and Skegg in both. I am chiefly interested in the difference between the models, which Atkinson and Skegg do not appear to recognize, but first the issue of the price variable must be resolved.

\section{Price}

There is still a striking relationship between price and consumption over the period 1951 to 1970 (Table II). The correspondence is quantitatively

TABLE II

ASSOCIATION BETWEEN ANNUAL CHANGES OF 'SIMPLE' PRICE AND CIGARETTE CONSUMPTION (1952-70)

\begin{tabular}{lllc}
\hline & & \multicolumn{2}{c}{ Price (Russell) } \\
& & Increase & Decrease \\
\cline { 2 - 3 } Consumption & Increase & 1 & 12 \\
Decrease & 6 & 0 \\
& & &
\end{tabular}

(If there is a tendency for large changes of both consumption and price to be followed by a return to the mean, this significance level may be exaggerated. However, the association is still remarkable.)

poor up to 1962 , and one year (1960) produced a marked anomaly, a consumption increase of $4 \%$ associated with a $2 \%$ price increase. However, since 1962 the correspondence has been quite precise (Figure) and the $2 \times 2$ significance over these eight changes is still significant $(P<0.02$, 1-sided). Moreover, this was a period of fluctuation; the signs of the consumption changes from 1963 to 1970 were +--+++-+ . In view of these results, it seems unreasonable to accept that the price elasticity is negligible.

Russell's price index was the price of standard untipped cigarettes divided by the cost of living

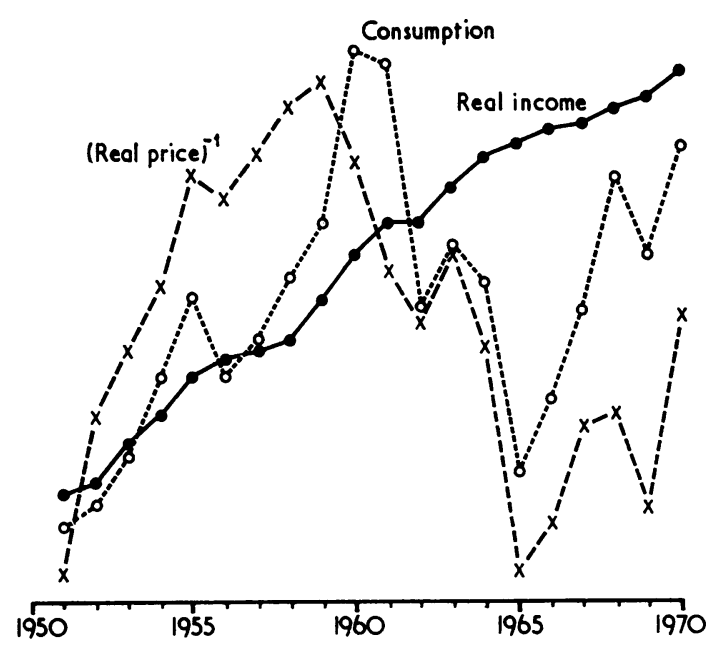

FIGURE Income, consumption and price ${ }^{-1}$ : arbitrary logarithmic scales.

index, but he remarked that it might have been preferable to allow for the marked shift to filter cigarettes that took place over this period. Atkinson and Skegg used an adjusted price variable designed to incorporate this and other effects, and it is interesting to compare the correspondence between this price index and consumption in the same way (Table III).

TABLE III

ASSOCIATION BETWEEN ANNUAL CHANGES OF ADJUSTED PRICE AND CIGARETTE CONSUMPTION (1952-70)

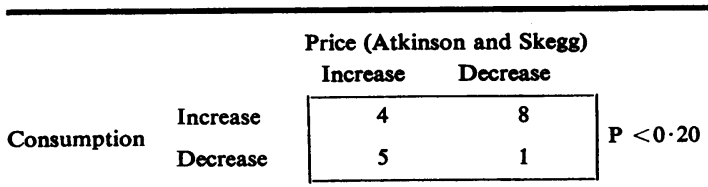

(The change from 1958 to 1959 is omitted, as the adjusted price variable did not change.)

Since there are no a priori grounds for selecting the optimal index of the effect of price changes on consumption the simplest measure may be preferable, particularly if it shows a substantially better relationship with consumption than more complex alternatives. It should be emphasized that this is not a matter of choosing the best estimator from a wide selection to demonstrate a non-existent relationship. Real price is the simplest reasonable index, and since it correlates so strikingly with consumption there can be little doubt that the effect is genuine. Atkinson and Skegg (1974) appear 
to reason in the opposite way; without commenting on this very significant association, they observe that when their adjusted price index replaces Russell's real price in (1) 'it reduces still further the coefficient of the price variable', apparently regarding this as confirmation of their choice of index.

I have therefore used Russell's price index throughout. However, the anomaly remains, for when Russell's price variable is substituted in equation (1) the estimated price elasticity is still only $-0.07 \pm 0.28$, while the other coefficients are virtually unaffected.

\section{INCOME}

Real incomes rose monotonically if not steadily between 1951 and 1970, so the relationship between consumption and income may be due at least in part to a coincidental rising trend in both. Replacing log (income) by a linear trend in equation (1) (i.e., assuming that consumption rose by a fixed proportion each year) gives a virtually identical fit $\left(R^{2}\right.$ falls by 0.006$)$. This analysis is shown in the second line of Table I. When income is included as well the improvement is negligible $\left(F_{1}, 13=0.9\right)$, indicating that fluctuations of consumption and income about the linear trend are unrelated. Moreover, when the linear trend is fitted the return trend following the publicity in 1962 and 1965 ceases to be significantly greater than zero, indicating that this may be a measure of the reduced growth of incomes since 1962 rather than anything to do with cigarette consumption, which continued to rise at the same rate as before, about $1 \%$ per annum. This is an important point; although such analysis is far from conclusive, it suggests that the effect of publicity is a permanent reduction rather than the transient fall described by Atkinson and Skegg. This could perhaps be resolved by survey data; if a large number of smokers reduced or gave up temporarily this would confirm the transience of the effect, while if many stopped for good the effect on consumption would be permanent. Thus, although it would be curious if price were effective but income were not (or vice versa), it does appear that income may not have the dominant effect which Atkinson and Skegg estimate.

\section{An Alternative Formulation}

If it is true that price influences consumption substantially and income may not, it is alarming that the opposite conclusion should emerge so conclusively from a careful conventional analysis. The error of measurement in econometric data based on large populations should be far less than the residuals that are typically obtained, and this is because the model is wrong rather than because normally distributed random error has been superimposed on the 'true' values.

Although large transient effects should be recognized and if possible attributed, the possibility of large drifts in mean value unrelated to identified social or economic forces can conceal direct and systematic responses, as they can produce very large residual errors. Equation (1) thus becomes:

4. $Q=\alpha Y+\beta P+\gamma_{1} d_{1}+\gamma_{2} d_{2}+\delta r+f(t)$, where $f(t)$ is a function unrelated to the predictor variables. Alternatively,

$$
\begin{aligned}
& \text { 5. } \Delta \mathrm{Q}=\alpha \Delta \mathrm{Y}+\boldsymbol{\beta} \Delta \mathrm{P}+\gamma_{1} \Delta \mathrm{d}_{1}+\gamma_{2} \Delta \mathrm{d}_{2}+ \\
& \delta \Delta \mathrm{r}+\Delta \mathrm{f}(\mathrm{t}) \text {, }
\end{aligned}
$$

$\Delta$ denoting the change from the previous year. The 'random error' is then $\Delta f(t)$, and if $f(t)$ is smooth there will be epochs of positive residuals followed by epochs of negative residuals. However, in other respects $\Delta f(t)$ behaves very like the classical random error of measurement in ordinary non-serial regression. Cumulative residual plots then give $\mathrm{f}(\mathrm{t})$ directly, and transient effects requiring independent explanation will manifest themselves as discontinuities. It is likely that the coefficients will themselves change over time, and this may generate local correlations between $\Delta f(t)$ and the predictor variables. Coefficients of the form $\alpha=\alpha(t)$ would presumably improve the fit, but such sophistication would tend to generate a spuriously good fit which would collapse on extrapolation. It is probably better to use the linear model and then examine the variance of $\Delta f(t)$ and its correlation with the predictor variables over the most recent part of the series before assigning confidence limits to any extrapolation.

\section{Models OF CONSUMPTION}

The models of consumer behaviour underlying equations (1) and (4) are very different. Equation (1) implies that for given values of price and income the consumption is accurately predictable, whether these conditions obtain in 1951 or 1970, and local variation is small and so unrelated to any systematic influence that the fit is rejected if residuals are serially correlated. Equation (4) implies that at any given time there is a more or less stable consumption pattern which can be influenced by changes of price or income, but the mean may drift considerably over periods of a few years. The weakness of the 
latter model is that the results will not be substantially affected if response to price and income changes is transient, followed by a slow return to the mean. However, if it is true that inexplicable mean drift occurs the first model may be more misleading. When the number of alternative formulations, transformations, and subsets of predictors applied by various authors approaches the number of data points, it is possible that what is being 'explained' by the most successful model is the inexplicable mean drift, and extrapolation will fail completely.

\section{The AnAlysis}

Fitting equation (5) using 'simple price' (first line of Table IV), the only variables showing significant association with consumption are price and the 1962 drop. Both income and the 1965 fall approach significance, and are therefore retained, but the return trend does not, and the analysis is repeated (second line of Table IV) without this term. There is a very large deviation at 1960 (a large value of $\Delta f(t))$, when both price and consumption rose. This corresponds to the largest annual increase in income of the period and is almost entirely responsible for the apparent dependence on income, for if this year is omitted (third line of Table IV), the dependence on income is negligible, and because the fit is improved the magnitude and significance of the price elasticity are considerably increased. This can be given a veneer of respectability by postulating that income changes do not affect consumption unless they exceed about $5 \%$. If the income variable, $\Delta Y$, is replaced by $\Delta Y-0.05$ for values greater than 0.05 and zero for lower values, the estimated coefficients are similar (fourth line of Table IV), for this is virtually equivalent to omitting the offending year, as this variable is zero for most other years. This dubious adjustment gives a better fit than the third line of Table IV where 1960 is omitted, confirming the suggestion that consumption rises when incomes increase so markedly that the change is perceived, although it would obviously fail for large income changes.

The largest price increase of the period occurred in 1965 , the year which saw the ban on television advertising, and here again the effects on consumption are inextricably confused. The 1965 drop is not significantly greater than zero, and when it is omitted from the equation (fifth line of Table IV) the estimated price elasticity increases still further. I am inclined to believe that this is an acceptable interpretation, for the ban on advertising might not be expected to have an immediate dramatic impact of the same magnitude as the wellpublicized campaign of 1962, but this conclusion must remain open.

Finally, the last line of Table IV shows the most tendentious overall analysis, fitting price, adjusted income, and the 1962 fall. I would defend the inclusion of this analysis, for since there is a marked and otherwise consistent response to price changes it appears that the 1960 change deserves independent explanation, and this is one way of supplying it; however, we are now well beyond the border between acceptable formal statistics and

TABLE IV

EQUATION (5): DEPENDENCE OF CIGARETTE CONSUMPTION CHANGES FROM PREVIOUS YEAR ON CHANGES OF PREDICTOR VARIABLES (1952-70)

\begin{tabular}{|c|c|c|c|c|c|c|c|}
\hline Equation & $\underset{\Delta \mathbf{P}}{\text { Price }}$ & $\underset{\Delta Y}{\text { Income }}$ & $\begin{array}{l}\text { Adjusted } \\
\text { Income }\end{array}$ & $\begin{array}{c}1962 \underset{\Delta d_{1}}{\text { Dummy }} \\
\text { (1) }\end{array}$ & $\begin{array}{c}1965 \text { Dummy } \\
\Delta d_{2}\end{array}$ & $\begin{array}{c}\text { Return } \\
\text { Trend } \\
\Delta \mathbf{r}\end{array}$ & $\begin{array}{l}\text { Multiple } \\
\text { Correlation }\end{array}$ \\
\hline 1. All variables & $\begin{array}{l}-0 \cdot 37 \\
(2 \cdot 2)\end{array}$ & $\begin{array}{l}0.46 \\
(1.8)\end{array}$ & - & $\begin{array}{c}-0 \cdot 052 \\
(2 \cdot 7)\end{array}$ & $\begin{array}{c}-0.036 \\
(1 \cdot 7)\end{array}$ & $\begin{array}{l}0.0057 \\
(0 \cdot 7)\end{array}$ & 0.876 \\
\hline 2. Omitting return trend & $\begin{array}{l}-0.37 \\
(2 \cdot 2)\end{array}$ & $\begin{array}{l}0.41 \\
(1.7)\end{array}$ & 一 & $\begin{array}{l}-0.057 \\
(3 \cdot 1)\end{array}$ & -0.033 & - & 0.871 \\
\hline $\begin{array}{l}\text { 3. Omitting return trend } \\
\text { and deleting } 1960\end{array}$ & $\frac{-0.50}{(3 \cdot 4)}$ & $\begin{array}{l}0.14 \\
(0.7)\end{array}$ & - & $\begin{array}{c}-0 \cdot 060 \\
(4 \cdot 0)\end{array}$ & $\begin{array}{l}-0.025 \\
(1 \cdot 5)\end{array}$ & - & 0.913 \\
\hline $\begin{array}{l}\text { 4. Omitting return trend } \\
\text { and modifying income } \\
\text { variable }\end{array}$ & $\begin{array}{l}-0.50 \\
(3 \cdot 6)\end{array}$ & - & $\begin{array}{l}4 \cdot 58 \\
(3 \cdot 7)\end{array}$ & $\begin{array}{l}-0.064 \\
(4.9)\end{array}$ & $\frac{-0.026}{(1 \cdot 6)}$ & - & 0.922 \\
\hline $\begin{array}{l}\text { 5. Omitting return trend } \\
\text { and } 1965 \text { dummy }\end{array}$ & $\begin{array}{l}-0.54 \\
(3 \cdot 7)\end{array}$ & $\begin{array}{l}0 \cdot 49 \\
(2 \cdot 0)\end{array}$ & 一 & $\frac{-0.049}{(2 \cdot 6)}$ & - & - & 0.843 \\
\hline $\begin{array}{l}\text { 6. Omitting return trend } \\
\text { and } 1965 \text { dummy, and } \\
\text { modifying income } \\
\text { variable }\end{array}$ & $\frac{-0.64}{(5 \cdot 4)}$ & - & $\begin{array}{r}5 \cdot 09 \\
(4 \cdot 0)\end{array}$ & $\begin{array}{l}-0.059 \\
(4.4)\end{array}$ & - & - & 0.907 \\
\hline
\end{tabular}


post hoc rationalization, and the reader must exercise his rational degree of belief without the help of significance tests.

\section{CONCLUSION}

Male cigarette consumption between 1951 and 1970 shows marked response to price changes. There is significant evidence of a fall of about $5 \%$ in consumption following the Royal College of Physicians report in 1962. The estimated fall when television advertising was banned in 1965 , about $3 \%$, is not significantly greater than zero. There is some evidence of response to income changes, but this is mainly attributable to the large increases in consumption and income in 1960, without which the estimated effect is minimal and not significantly greater than zero. There is a rising trend in consumption, which may be attributable to the rise in income over this period. Since there was a large price increase in 1965 it is impossible to know whether the increase in estimated price elasticity which follows the omission of the 1965 dummy variable is genuine. Similarly, if the apparently anomalous increase in consumption in 1960 is attributed to some external cause the estimated elasticity is further increased. The estimates thus range from -0.37 to -0.64 . Although the persistence of all these responses remains uncertain, it thus seems likely that systematic tax increases would have an immediate and progressive effect on consumption and recruitment, particularly among young people, who are less wealthy and less addicted. Although health education has some impact, there seems to be no other way of reducing smoking on the scale demanded by the still mounting evidence of associated morbidity and mortality. Such a step might be politically acceptable if the increased revenue were used to subsidize some specific essential such as butter or milk.

\section{REFERENCES}

Atkinson, A. B. and SkegG, J. L. (1973). Anti-smoking publicity and the demand for tobacco in the U.K. Manchester School, 41, 265. _ and - (1974). Control of smoking and price of cigarettes-a comment. Brit. J. prev. soc. Med., 28, 45.

Russell, M. A. H. (1973). Changes in cigarette price and consumption by men in Britain, 1946-71: a preliminary analysis. Brit. J. prev. soc. Med., 27, 1. 